\title{
SEMIÓTICA APLICADA: CAMPANHA PUBLICITÁRIA JOURNEY, COM ANGELINA JOLIE, SOB O ESPECTRO DA TEORIA PEIRCEANA
}

\author{
Applied semiotics: hype Journey with Angelina Jolie under the specter of peircean \\ theory
}

\author{
Semiótica aplicada: campaña publicitaria Journey con Angelina Jolie, bajo la \\ teoría de espectro peirceana
}

\author{
Carolina Boari Caraciola ${ }^{1}$
}

\begin{abstract}
Resumo
O presente artigo analisará uma peça da campanha publicitária Journey, da marca de luxo Louis Vuitton, estrelada pela atriz Angelina Jolie, sob o prisma da semiótica de extração peirceana. A análise da publicidade, sob o espectro da teoria semiótica, permite explicitar o potencial comunicativo do anúncio a que se refere, uma vez que as estratégias semióticas utilizadas por uma marca são fatores essenciais à sua constituição como marca, sendo, portanto, de fundamental importância para a compreensão de sua natureza, perfil e efeitos emocionais e funcionais.
\end{abstract}

Palavras-chave: publicidade, semiótica peircena, luxo, Louis Vuitton.

\begin{abstract}
This article will examine an advertising campaign piece Journey, the luxury brand Louis Vuitton, starring the actress Angelina Jolie, in the light of Peirce's semiotics extraction. Analysis of advertising, in the spectrum of semiotic theory, allows explicit communicative announcement potential referred to, since the semiotic strategies used by a brand are essential to its constitution as a brand, it is therefore of fundamental importance for understanding its nature, profile and emotional and functional effects.
\end{abstract}

Keywords: advertising, peircean semiotics, luxury, Louis Vuitton.

\footnotetext{
${ }^{1}$ Doutora em Comunicação e Semiótica pela Pontifícia Universidade Católica de São Paulo (PUC/SP), com a tese "Evolução, significados e marketing publicitário do luxo. Estudo de caso da marca Louis Vuitton sob o prisma da semiótica". Pesquisadora do mercado de luxo. Atua como docente no curso de Publicidade e Propaganda da Faculdade Paulus de Tecnologia e Comunicação (FAPCOM). email: carolboari@yahoo.com.br
} 
Semiótica aplicada: campanha publicitária Journey, com Angelina Jolie, sob o espectro da teoria peirceana

de Carolina Boari Caraciola

\section{Resumen}

En este artículo examinaremos una pieza campaña de publicidad Journey, la marca de lujo Louis Vuitton, protagonizada por la actriz Angelina Jolie, a la luz de la extracción de la semiótica de Peirce. Análisis de la publicidad, en el espectro de la teoría semiótica, permite que el potencial comunicativo anuncio explícito se refiere, ya que las estrategias utilizadas por los semióticos una marca son esenciales para su constitución como una marca, por lo tanto, es de fundamental importancia para la comprensión de su naturaleza, el perfil y efectos emocionales y funcionales.

Palabras-clave: publicidad, semiótica peircena, lujo, Louis Vuitton.

\section{CONSIDERAÇÕES SOBRE O MÉTODO DE ANÁLISE}

A análise da peça publicitária da campanha Journey, da marca de luxo Louis Vuitton, protagonizada pela atriz Angelina Jolie, partirá da fenomenologia, cuja função é " [...] apresentar as categorias formais e universais dos modos como os fenômenos são apreendidos pela mente" (Santaella 2012:07). Tais categorias são denominadas como primeiridade, secundidade e terceiridade.

A primeiridade relaciona-se ao acaso, é uma simples possibilidade, um ato contemplativo de imersão na qualidade e no sensível. Na primeiridade, há uma sugestão, ou evocação como possibilidade de funcionar como signo. Nesse momento de contemplação, as referências são abandonadas, procurando, apenas, apreender o modo como o fenômeno se apresenta. O sentimento, na primeiridade, é vago, não havendo a mediação de outros signos. Os signos de primeiridade são denominados quali-signos, ou seja, o poder de sugestão de uma qualidade possibilita o funcionamento do signo.

A secundidade relaciona um fenômeno primeiro a um segundo, estando ligada às ideias de força bruta, ação e reação, conflito, resistência, esforço, aqui e agora. $\mathrm{O}$ estado contemplativo se esvai e o fenômeno se apresenta como realidade concreta, na sua natureza de sin-signo, um signo de existência, “[...] onde 'sin' quer dizer singular" (Santaella 2012:13). Secundidade começa quando um fenômeno primeiro é relacionado a um segundo fenômeno qualquer (CP 1.356-359). É a categoria da ação, do fato, da realidade e da experiência no tempo e no espaço: "Ela nos aparece em fatos tais como o outro, a relação, compulsão, efeito, dependência, independência, negação, ocorrência, realidade, resultado." (Nöth 2003:64) 
Semiótica aplicada: campanha publicitária Journey, com Angelina Jolie, sob o espectro da teoria peirceana

de Carolina Boari Caraciola

A terceiridade representa o efeito que o signo provocará em um possível interpretante. Os signos de terceiridade são denominados de legi-signos, em função de seu caráter de lei. Na terceiridade, os fenômenos são interpretados a partir de associações advindas de conhecimento prévio, as experiências colaterais. A terceira categoria corresponde à definição de signo genuíno, pois este é capaz de produzir outro signo, o que corresponde ao processo de semiose infinita; sendo assim, a terceiridade é um processo de crescimento contínuo. Terceiridade é a categoria que relaciona um fenômeno segundo a um terceiro (CP 1.377/ss): “É a categoria da mediação, do hábito, da memória, da continuidade, da síntese, da comunicação, da representação, da semiose e dos signos.” (Nöth 2003:64)

A análise da peça publicitária terá início a partir do ponto de vista qualitativoicônico, detendo-se aos aspectos qualitativos da publicidade, tais como cores, linhas, texturas, formas, volume, movimento, aspectos presentificados em uma primeira apreensão, ou seja, referem-se "[...] à impressão que brota da primeira olhada". Esse primeiro nível de análise também desperta qualidades abstratas, bem como a previsão de "[...] associações por semelhança que essas qualidades estão aptas a produzir" (Santaella 2012:70). As relações de associações por semelhança são denominadas icônicas.

Em seguida, o ponto de vista singular-indicativo analisará o anúncio como algo existente em espaço e tempo determinados. As qualidades existentes serão examinadas de acordo com sua manipulação e uso.

Por último, o ponto de vista convencional-simbólico analisará o "poder representativo do produto", no caso em questão, da publicidade, o que ela simboliza, os valores culturais que lhe foram transferidos, a imagem da marca e, de qual maneira a publicidade “[...] está contribuindo ou não para a construção ou solidificação da marca". (Santaella 2012:71).

As análises seguirão esses três pontos de vista mencionados anteriormente como guias de observação. Mas, inevitavelmente, em alguns momentos, os aspectos qualitativos-icônicos, singulares-indicativos e convencionais-simbólicos escorregam uns para os outros, pois secundidade pressupõe primeiridade e terceiridade pressupõe ambas. Isso significa que a análise será tanto mais justa quanto mais puder evidenciar esse processo que se assemelha a uma caixinha chinesa. 
Semiótica aplicada: campanha publicitária Journey, com Angelina Jolie, sob o espectro da teoria peirceana

de Carolina Boari Caraciola

A imagem escolhida faz parte de um campo visual delimitado pelos contornos da fotografia, sendo que os elementos “[...] são visíveis até um ângulo limitado para a direita e esquerda e ainda mais limitado para cima e para baixo" (Santaella 2005:185186). A fotografia da campanha utiliza o sistema ocidental de leitura, ou seja, da esquerda para a direita, na diagonal de cima para baixo, sendo que o nome da marca está colocado embaixo, na parte direita da imagem. A assinatura da campanha é o nome Louis Vuitton, escrito por extenso, sem o logotipo da grife. O nome da marca, bem como a legenda, que se diferenciam de acordo com cada anúncio, representam a parte verbal da publicidade.

O nome da marca, homônimo ao de seu fundador, é carregado de referências que se relacionam à tradição, ao luxo, à sofisticação e distinção, estando posicionado no canto inferior direito dos anúncios, gerando um efeito espelho em relação à celebridade. Dessa relação, pode-se concluir que a marca confere diferenciação a seus usuários, ocorrendo um processo de transferência de significado por similaridade. "O consumidor de repente 'enxerga' a similaridade entre a celebridade e o produto e está preparado para aceitar que os significados da celebridade estão no produto." (McCracken 2012:122)

Nesse contexto, o nome da marca funciona como um signo genuíno, ou seja, um símbolo. Ele, “[...] além de sua função verbal [...] possui uma dimensão não-verbal, icônica, que incorpora, por conotação, significados complementares ao próprio nome." (Perez 2004:53)

O nome da marca, escrito por extenso, lettering, é utilizado em letras maiúsculas, caixa alta, o que confere estabilidade, em função da manutenção de sua forma, sendo uma fonte sem serifas, similar à Futura, com legibilidade apropriada, em função de sua construção geométrica. As qualidades da tipografia que desenham o nome Louis Vuitton geram um efeito de sentido positivo ao serem transferidas à marca, corroborando seus valores de tradição, estabilidade, qualidade, elegância, sobriedade. A cor preta, utilizada no lettering, remete à tradição da marca e sua elegância. "[...] a renúncia às cores permite que o luxo se manifeste por si só [...] o preto é a mais nobre das cores." (Heller 2013:150)

Soma-se, a isso, o uso da cor branca, como fundo para o nome da marca, que na esfera emocional gera efeitos tais como sofisticação, moda, luxo, status, glamour. O branco remete à limpeza, sendo considerada a cor da verdade, do estilo minimalista, é 
Semiótica aplicada: campanha publicitária Journey, com Angelina Jolie, sob o espectro da teoria peirceana

de Carolina Boari Caraciola

imaculada. "O branco como cor proeminente, é usado também por reis e rainhas nas ocasiões mais importantes [...].”(Heller 2013:150)

A grafia da marca Louis Vuitton se assemelha, por similaridade, com a inscrição do nome de Luís XIV, o rei Sol, nos textos da época da monarquia, que se referiam ao rei como LOUIS LE GRAND "[...] era assim, em letras maiúsculas, que seu nome figurava frequentemente no meio de textos em caixa baixa." (Burke 1994:47)

Portanto, a referida campanha será analisada sob a perspectiva da semiótica peirceana, com o escopo de identificar quais são as características, os traços e os atributos específicos apresentados na publicidade da marca de luxo Louis Vuitton, campanha Journey, veiculada no ano de 2011, com a atriz Angelina Jolie. [...] as relações entre marketing, publicidade e semiótica estão a cada dia mais evidentes, tendo em conta a complexificação da nossa sociedade que cada vez mais consome símbolos construídos em grande parte pela publicidade do mundo capitalista. (Perez 2004:142)

Sendo assim, marca Louis Vuitton aqui funciona como signo, aliás um signo complexo, como são complexos quase todos os signos, uma vez que o objeto dinâmico é aquele que determina o signo e que este tem a função de representar todo o contexto histórico e evolução no tempo da marca Louis Vuitton, sendo então, o objeto dinâmico dessa marca. As campanhas e peças publicitárias são signos constitutivos da complexidade do signo maior que é a marca Louis Vuitton.

A marca Louis Vuitton apresenta como principal diferencial a tradição, possuindo uma história que, desde o princípio, esteve relacionada à realeza. A maison explora um posicionamento de superioridade no que tange à qualidade e sofisticação dos produtos que oferta, trabalhando com uma comunicação integrada, de modo a evidenciar seus principais atributos.

\section{CAMPANHA JOURNEY - ANGELINA JOLIE, 2011}

A campanha publicitária Journey, da marca Louis Vuitton, foi também protagonizada, entre outros, pela atriz americana Angelina Jolie, veiculada no ano de 2011, produzida pela agência de publicidade Ogilvy \& Mather, de Paris, e fotografada por Annie Leibovitz, no Camboja. 
Semiótica aplicada: campanha publicitária Journey, com Angelina Jolie, sob o espectro da teoria peirceana

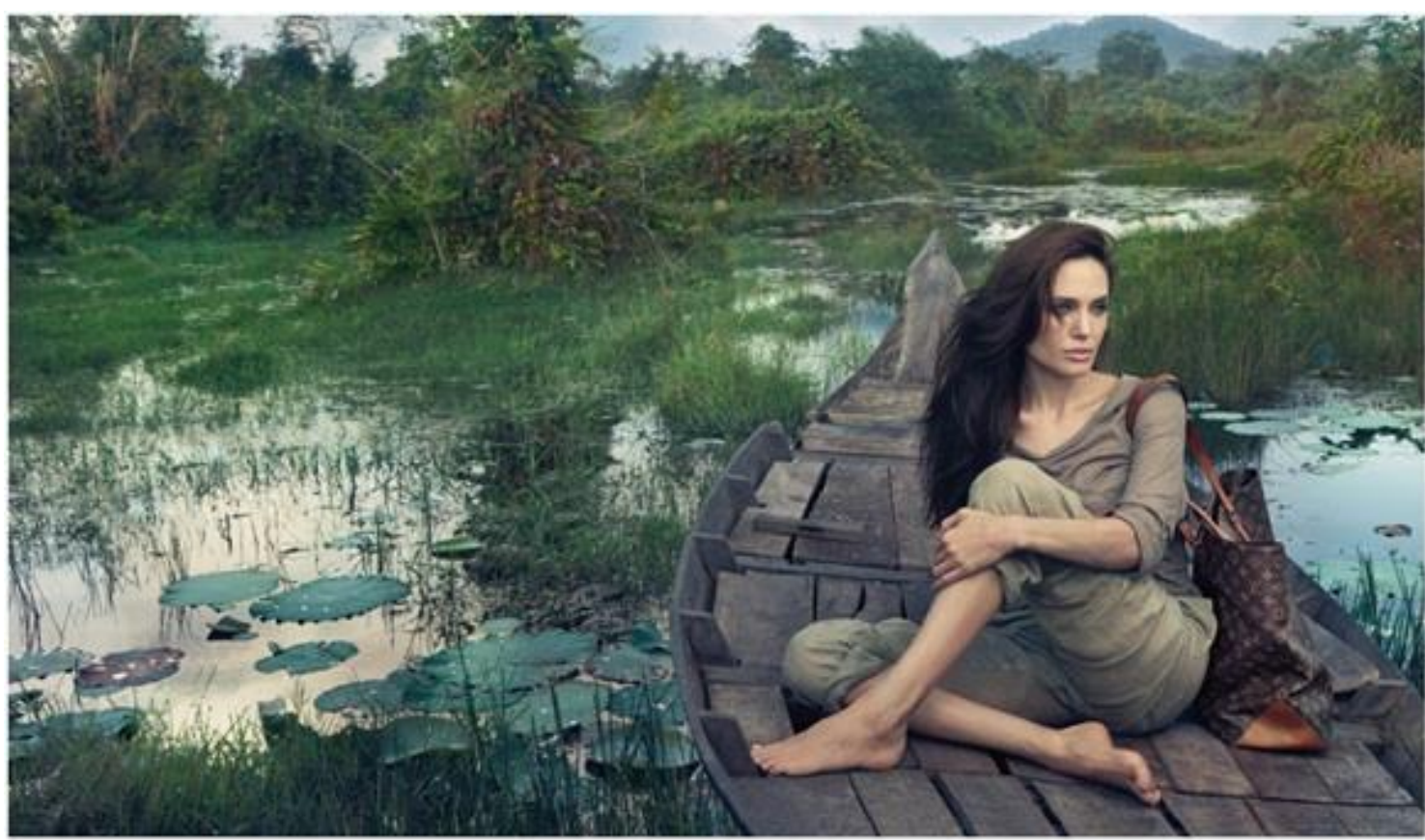

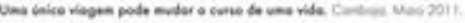

LOUIS VUITTON

Figura I - Campanha Journey, Louis Vuitton, com Angelina Jolie (2011)

\subsection{O ponto de vista qualitativo - icônico}

O ponto de vista qualitativo-icônico nos induz à contemplação da imagem. "A leitura tem início pelos aspectos qualitativos, aqueles aspectos que falam aos sentidos, que produzem impressões relativas ao modo como algo se apresenta à percepção.” (Santaella 2010:220)

Os signos, nesse nível, são denominados quali-signos, pois são vistos como pura qualidade. Quali-signos se referem à composição intrínseca do signo, sua aparência. Quali-signos são ícones na relação com seus objetos, isso porque representam o que podem representar tão só e apenas devido às qualidades que exibem, qualidades estas que podem apresentar correspondência com outras qualidades, quando passam a funcionar com signos. Já na relação dos quali-signos com seus interpretantes, eles são interpretados como remas, ou seja, hipóteses interpretativas. Por isso, quando interpretamos ícones, sempre usamos verbos como evocar, sugerir, parecer etc.

Portanto, nesse primeiro momento, o que se busca é perceber como as qualidades, tais como cores, formas, texturas, luminosidade, dimensão, entre outras, despertam sentimentos e associações. 
Semiótica aplicada: campanha publicitária Journey, com Angelina Jolie, sob o espectro da teoria peirceana

de Carolina Boari Caraciola

A imagem do anúncio pode ser dividida em dois planos. No primeiro plano, posicionado ao lado direito, é possível vislumbrar a figura de uma mulher, descalça, sentada em um barco de madeira, usando roupas simples e casuais, sugerindo simplicidade e estranha familiaridade com o local no qual se encontra.

Elementos com diversas superfícies são apresentados, havendo predomínio da textura rústica, tanto da vegetação, quanto da madeira do barco, bem como das vestes da moça. As texturas podem ser entendidas como os "[...] aspectos da trama e do entrelaçamento das fibras que constituem a superfície [...]" (Oliveira \& Garcez 2004:53). A textura da madeira se mostra rústica, havendo uma ponta que direciona o olhar para o fundo da imagem, no qual é possível perceber uma possível montanha. No barco há algumas folhas pequenas, caídas atrás da modelo, o que sugere a troca de estação, em um clima ameno, em uma temperatura agradável.

A imagem apresenta o predomínio de linhas orgânicas, o que deixa a composição mais descontraída. A linha curva, formada pelo contorno do barco, conduz o olhar do espectador para cima, trazendo a sensação de movimento. A linha é uma marca contínua, sendo “[...] o sinal mais versátil, pois pode sugerir movimento e ritmo, comunicar sentimentos e sensações" (Oliveira \& Garcez 2004:50). Percebe-se o uso de uma disposição particular dos elementos no espaço visual para proporcionar enfoque ao tema e ao produto de modo sutil, conforme a análise que segue.

A imagem segue a regra dos três terços, cujo objetivo é capturar uma imagem visualmente equilibrada e agradável de se ver. A regra dos terços possibilita o melhor enquadramento da imagem, através de um exercício visual, no qual o fotógrafo, mentalmente, divide a imagem em três terços verticais e três terços horizontais, totalizando nove enquadramentos, conforme apresentado na figura abaixo. Desta forma, os elementos a serem mais destacados, ficarão posicionados nas intersecções entre as linhas, os denominados pontos de ouro. "Sendo assim, ao invés de centralizar o assunto, ele será posicionado nestes pontos, o que dará à foto uma composição mais elaborada. O objetivo é conseguir uma maior harmonia entre os elementos da foto.”2

Sendo assim, o rosto da mulher está posicionado próximo ao vértice superior direito do retângulo central, o que consiste em um ponto focal de destaque.

\footnotetext{
${ }^{2}$ Disponível em: <http://www.infoescola.com/fotografia/regra-dos-tercos/>. Acesso em: 29 dez 2014.
} 
Semiótica aplicada: campanha publicitária Journey, com Angelina Jolie, sob o espectro da teoria peirceana

de Carolina Boari Caraciola

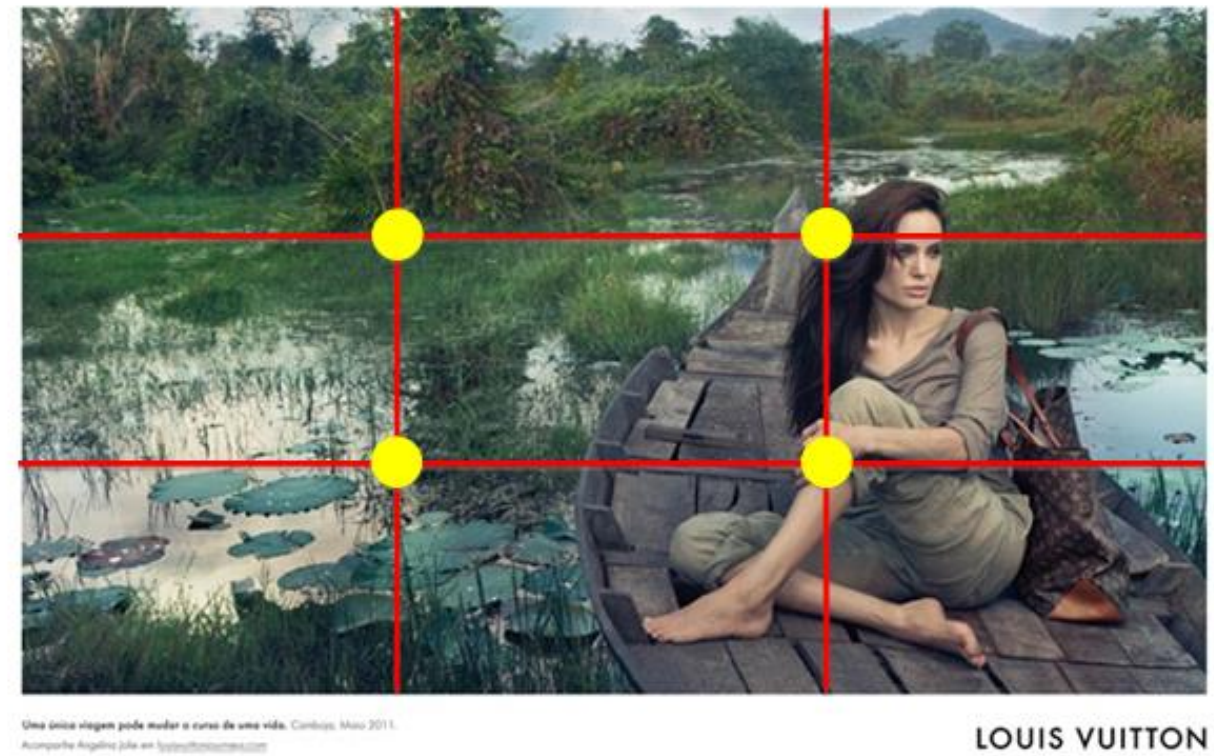

Partindo das considerações sobre composição visual feitas por Arnheim (2014), pode-se considerar a figura um triângulo deslocado do centro do espaço em primeiro plano. Essa forma geométrica é formada pelo barco, pela mulher e por sua bolsa. O cruzamento de suas pernas também forma a mesma figura geométrica, o que pode ser demonstrado a seguir.

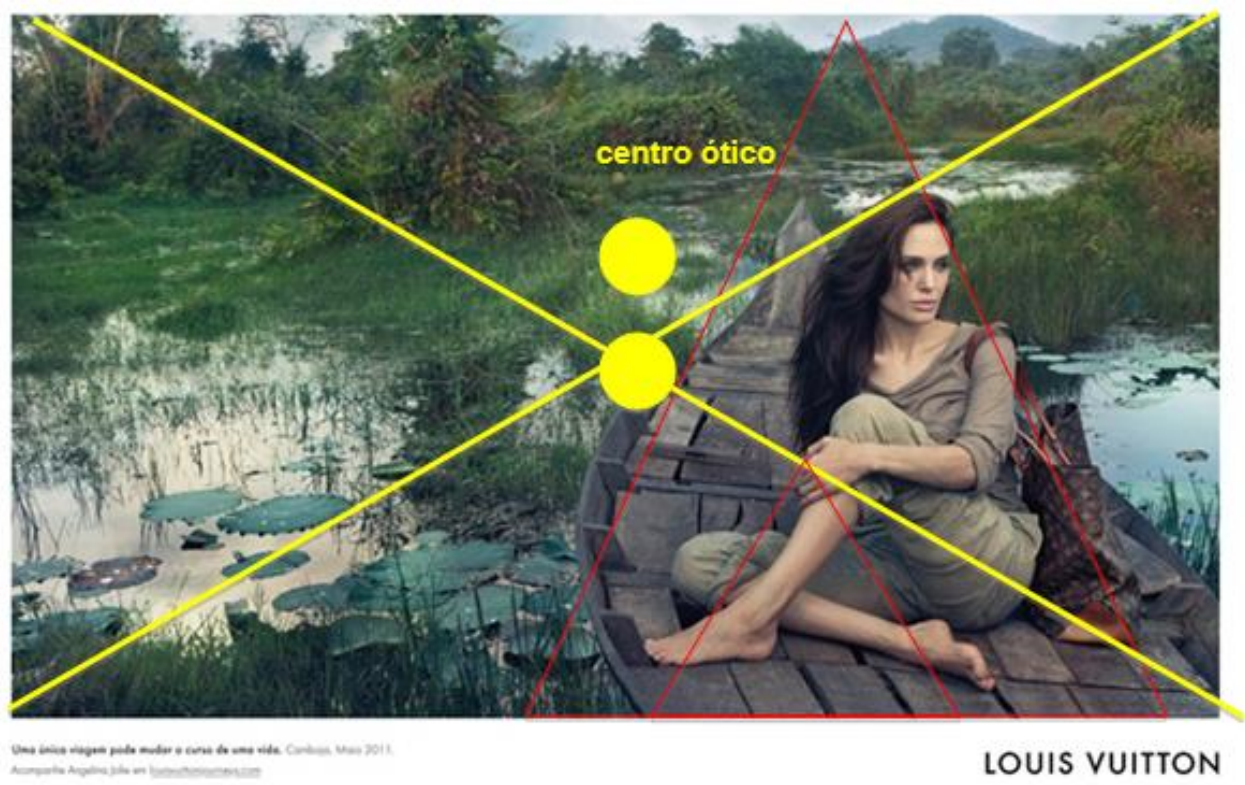


Semiótica aplicada: campanha publicitária Journey, com Angelina Jolie, sob o espectro da teoria peirceana

de Carolina Boari Caraciola

É possível perceber, analisando a composição visual, que o barco, a mulher e a bolsa formam um triângulo deslocado do centro do espaço, no primeiro plano. Tal modo de distribuição dos elementos é característico do período renascentista, em que as figuras em primeiro plano eram dispostas de modo a formarem um triângulo no centro do espaço.

No anúncio em análise, a composição do primeiro plano está deslocada do centro, justamente para criar um efeito mais dinâmico, sugerindo mobilidade, o que serve para corroborar o tema das viagens. Embora o primeiro plano da imagem esteja deslocado, o fundo se mostra preenchido por vegetação, o que cria um equilíbrio simétrico na composição da foto. O rosto da mulher está na linha do centro geométrico, o que favorece sua rápida identificação. A vegetação de fundo não está desfocada, proporcionando um equilíbrio simétrico no espaço.

A luz foi trabalhada conforme o uso convencional das pinturas renascentistas, utilizada de maneira frontal, ou vinda de cima, iluminando a imagem como um todo. A luz também possibilita o destaque da vegetação, contribuindo para uma visualização mais simétrica da imagem.

O anúncio parece estabelecer uma relação de associação por similaridade com a obra de arte renascentista, Mona Lisa, de Leonardo da Vinci, o quadro mais famoso da história da arte. Analisando as duas imagens, percebe-se similaridade entre a constituição dos fundos, a vegetação, bem como a presença de uma montanha.

O fundo das duas imagens, a do anúncio e a da Mona Lisa, apresenta características comuns; as vegetações presentes nos lados direitos são mais baixas que as do lado esquerdo, o que justifica o posicionamento da mulher e seu maior destaque. Porém, enquanto o cenário de Da Vinci é construído, o do anúncio é real e bastante significativo para a interpretação da campanha.

Ambas, Gioconda e a mulher que no anúncio se apresenta, aparecem com semblantes contemplativos, porém, enquanto a primeira olha diretamente para 0 receptor, a segunda desvia seu olhar, evocando mais introspecção. A mulher que, no anúncio publicitário, pode ser associada à Mona Lisa, personifica os requisitos de perfeição e beleza da contemporaneidade: alta, magra, jovem, olhos grandes e de pele clara, um resquício de beleza nobre (Tungate 2013). 
Semiótica aplicada: campanha publicitária Journey, com Angelina Jolie, sob o espectro da teoria peirceana

de Carolina Boari Caraciola

As cores da imagem foram trabalhadas de maneira intensa. $\mathrm{O}$ fundo, composto pela vegetação, apresenta diversos tons esverdeados e azulados, enquanto os tons do barco e das roupas são terrosos, funcionando como tons neutros para não ganharem mais destaque do que a bolsa, cuja cor marrom mais forte se destaca na composição cromática. Dessa forma, a cor cria um ponto focal diferenciado para a mercadoria, funcionando também como um índice na relação com a bolsa que a atriz carrega em seu ombro, sendo possível reconhecer as siglas LV, em função das cores mais chamativas do material, marrom escuro e bege.

As cores apresentadas na imagem revelam um contraste entre suas temperaturas. Enquanto os tons esverdeados e azulados são frios, os tons terrosos transmitem uma sensação de temperatura mais quente, havendo uma reação mais dinâmica ao observálos. "Estamos descrevendo uma qualidade que emana no objeto bem como nossa reação a essa qualidade." (Arnheim 2014:360)

A mulher está olhando para o infinito, com semblante sereno, aparentemente sem maquiagem, o que sugere naturalidade, sensação aumentada pela presença da vegetação ao seu redor. Os cabelos mostram-se levemente ondulados, o que sugere movimento. O olhar da modelo não foca a câmera, ou seja, não dialoga com o receptor da mensagem, o que sugere ensimesmamento. A moça está sentada e seus pés estão dispostos em sentidos contrários. A mão esquerda está sob o joelho esquerdo e a mão direita não aparece, sugerindo que essa mão está servindo de apoio ao resto do corpo. A modelo se mostra confortável e adaptada ao local no qual está inserida.

O primeiro plano da imagem, ao lado esquerdo, bem como todo o segundo plano são compostos por vegetação com tons verdes e azulados que, em alguns pontos específicos, se torna mais aberta, possibilitando a visualização da água na qual o barco flutua. A água transmite a ideia de movimento e leveza, em um ritmo bastante lento e calmo.

A profundidade do espaço visual é enfatizada através da linha curva do barco, que aponta para o fundo da composição. Em alguns pontos, a vegetação é mais densa e alta, formando um cenário natural que vai direcionando o olhar para a montanha ao fundo da imagem.

Em suma, a composição da imagem sugere quietude, contemplação, serenidade, intimismo, introspecção, naturalidade, simplicidade, desprendimento. Vejamos, a seguir 
Semiótica aplicada: campanha publicitária Journey, com Angelina Jolie, sob o espectro da teoria peirceana

de Carolina Boari Caraciola

como esses aspectos encontram complementação nos outros dois aspectos do signo sob análise.

\subsection{O ponto de vista singular - indicativo}

Sob o ponto de vista singular-indicativo a imagem é analisada no seu estatuto de existente singular. Essa imagem que se apresenta diante de nós, suas referências ao contexto no qual está inserida e as funções que desempenha.

O objeto em análise é também um anúncio publicitário da campanha Journey, da Louis Vuitton. A linguagem do anúncio é fotográfica, como é comum acontecer em imagens publicitárias, o que faz com que elas se constituam em legi-signos, pois corporificam um padrão que as tornam reconhecíveis como anúncios. Mas, em cada foto particular sempre domina o aspecto indicial, pela conexão dinâmica entre o objeto e a tomada que são constitutivos do signo fotográfico.

Nesse segundo momento, é fácil constatar que a mulher fotografada é Angelina Jolie, e que os elementos fotografados, tais como o barco, a vegetação, a montanha, a atriz, a bolsa e todos os demais itens existem na realidade, lá estavam fora da captura da tomada da foto. É a concretude de tais componentes que fundamenta os índices. Sendo assim, para que a imagem da atriz, por exemplo, esteja presente no anúncio, houve uma óbvia conexão entre Angelina e a fotografia. O anúncio, bem como os elementos nele presentes, conecta-se aos objetos existentes, fazendo que esse signo gere um interpretante dicente, ou seja, um signo de existência concreta.

O anúncio apresenta uma antítese visual em sua sustentação, o que causa, em um primeiro momento, um estranhamento. Angelina Jolie, ícone de glamour feminino, destaque em revistas por sua beleza e presença em eventos, sempre elegante e bem vestida, aparece, na publicidade, de maneira natural, simples, desprovida de uma grande produção, gerando um conflito entre a imagem captada e aquelas que são veiculadas pela grande mídia. Para decifrar esse estranhamento, é necessário recorrer ao objeto dinâmico da foto, aquilo que essa foto apresenta, indica e representa.

Angelina é a celebridade mais nova de todas as que participaram da campanha Journey, possuindo forte apelo de massa, em função dos filmes nos quais atuou em Hollywood, como Tomb Raider, no qual deu vida à personagem de videogame, Lara Croft, o que justifica a escolha de uma bolsa em seu anúncio, acessório considerado um 
Semiótica aplicada: campanha publicitária Journey, com Angelina Jolie, sob o espectro da teoria peirceana

de Carolina Boari Caraciola

produto de introdução ao universo do luxo. A bolsa é um artigo fundamental para uma mulher, pois conta sua história, carrega seus objetos pessoais, sendo o índice que a identifica mais imediatamente, revelando sua identidade através da marca, das cores, da textura, do modo de usar. "Não importa. Hoje em dia, mais do que qualquer outra coisa, a bolsa conta a história da mulher: sua realidade, seus sonhos. E, graças ao marketing das marcas de luxo, essa bolsa muda depois de alguns meses, como as estações, como seu estado de espírito.” (Thomas 2008:151)

O produto em questão é de uso particular de Angelina, e está descontinuado, ou seja, não disponível para a venda, o que revela o objetivo de vincular a imagem da marca aos conceitos de altruísmo, benevolência, causas sociais, e não somente a vendas. Assim como a bolsa, as vestes da atriz são de uso pessoal, transmitindo a ideia de legitimidade na escolha da modelo, representando um endosso explícito que objetiva transferir os atributos de Angelina, tais como beleza, sofisticação e engajamento, ao produto.

Contudo, a biografia de Angelina é clara ao relatar que ela nem sempre foi considerada um ideal de comportamento. $\mathrm{O}$ início de sua carreira foi marcado por episódios de automutilação, internações por problemas mentais, uso de drogas, sendo considerada uma celebridade descontrolada. "[...] quando ainda estava na adolescência, Angelina foi rotulada de psicopata." (Halperin 2012:43). Dessa forma, será que a escolha de Angelina como representante da Louis Vuitton poderia prejudicar a marca? A resposta vai justamente em direção contrária.

A carreira de Jolie foi se consolidando, ela ganhou uma série de prêmios, incluindo o Oscar de melhor atriz coadjuvante por Garota Interrompida, no ano 2000. No mesmo ano, Angelina começou a gravar Tomb Raider, no Camboja, sendo impactada pelo sofrimento humano do local, fato que modificou sua visão de mundo. "Ao retornar a Hollywood, achou difícil olhar para a sua vida da mesma maneira, novamente. Agora, ela havia, como mais tarde declarou, 'encontrado um propósito'." (Halperin 2012:219)

A imagem maculada de Jolie foi se desfazendo a partir do momento em que se tornou uma celebridade engajada em causas sociais. "[...] associar um ator ou atriz a uma causa humanitária é um dos métodos mais efetivos de reparar ou transformar uma imagem manchada." (Halperin 2012:238). No ano de 2001, Angelina recebeu o título de Embaixadora da Boa Vontade das Nações Unidas, ação que foi vista, a princípio, como 
Semiótica aplicada: campanha publicitária Journey, com Angelina Jolie, sob o espectro da teoria peirceana

de Carolina Boari Caraciola

mera estratégia de promoção de sua carreira, percepção revista em função da dedicação da atriz a causas humanitárias.

As Nações Unidas, até então, somente escolhiam celebridades de reputação inabalada para o posto de embaixadora, porém, com o objetivo de atrair um público mais jovem, nomeou Angelina para o cargo. A atriz passou a dedicar tempo e dinheiro a causas humanitárias. Visitou lugares como Paquistão, Bósnia, Iraque, Jordânia, e África a fim de direcionar sua fama para a questão dos necessitados. Em novembro de 2001, Angelina adotou um órfão no Camboja, rebatizando-o de Maddox Chivan, alterando definitivamente sua imagem, de polêmica e rebelde para uma mãe zelosa e solidária.

A fotografia de Angelina Jolie para a campanha Journey foi feita no Camboja, país pobre localizado no Sudeste Asiático, carregado de significados expressivos para a atriz, justificando a legenda "Uma única viagem pode mudar o curso de uma vida".

A propaganda com Angelina foi bastante criticada em função de especulações sobre o apagamento de 10 milhões de dólares para a atriz, sendo que uma parte desse valor seria destinado para as ações humanitárias das quais participa. Tal hipótese não foi confirmada por nenhuma das partes envolvidas,

A posição na qual Angelina se encontra na campanha não permite que suas tatuagens sejam vistas, ou seja, suas marcas do passado são ocultadas.

O cenário simples, porém significativo para a atriz, serve como moldura para Angelina aparecer deslumbrante, sem máscaras, sendo possível entender que a verdadeira beleza está na atitude, na autoconfiança, e que tais qualidades são intrínsecas a quem possui uma bolsa Louis Vuitton. O destaque das cores marrom e bege corrobora tal pensamento, uma vez que essas cores evocam a identidade da marca Louis Vuitton, funcionando como fortes traços de identificação.

A parte verbal do anúncio é composta pela inscrição do nome da marca, Louis Vuitton, e pela legenda: "Uma única viagem pode mudar o curso de uma vida". Através de uma associação por contiguidade, o anúncio tenta associar o produto, no caso, a bolsa, a uma transformação decorrente de uma viagem que transformou a vida de Angelina e modificou sua imagem. "[...] Nas imagens, a sugestão, presente na transmissão de valores associados a certos objetos, torna necessário que eles sejam mostrados lado a lado do produto." (Santaella \& Nöth 2010:134). Tais afirmações, para serem interpretadas corretamente, requerem um conhecimento prévio, uma experiência colateral com o objeto dinâmico, a mulher real, para nós, em suas aparições 
Semiótica aplicada: campanha publicitária Journey, com Angelina Jolie, sob o espectro da teoria peirceana

de Carolina Boari Caraciola

evidentemente também sígnicas, do signo complexo Angelina Jolie, como foi visto anteriormente.

\subsection{O ponto de vista convencional - simbólico}

A campanha Journey, da Louis Vuitton, é um meio privilegiado para se transmitir e persuadir os valores simbólicos contidos na marca, argumentando, de forma direta ou indireta, seus objetivos:

[...] dirige-se, também, às zonas não inteiramente conscientes do psiquismo do consumidor, e atinge desejos, até então, desconhecidos pelo próprio comprador. Ela não pretende, simplesmente, informar ou convencer, em vez disso, quer, também, sugerir e atingir seu objetivo: a compra de um produto, escamoteando esse objetivo (Santaella \& Nöth 2010:97)

A veiculação de uma propaganda deve apresentar alguns objetivos, tais como, aponta Perez (2004): ser informativa, persuasiva, memorizada e agregar valor à mercadoria. Informar sobre a existência do produto é essencial para que o consumidor o conheça e, posteriormente, se interesse. No que tange à persuasão, a publicidade tem como objetivo influenciar o consumidor, levando-o à ação de compra. A função de lembrança busca trazer para a mente do consumidor uma rede associativa de significantes que fogem da mente consciente.

As bolsas, no segmento de luxo, são produtos fáceis de serem vendidos, não demandam prova, possibilitam um primeiro contato com o setor, sendo lucrativos para a própria empresa, pois o preço de venda é bem maior do que o custo de fabricação. A Louis Vuitton, por exemplo, obtém um lucro de até treze vezes em relação aos gastos com produção do produto. (Thomas 2008:152)

Os referidos acessórios se tornaram produtos propulsores das marcas de luxo e se renovam com grande rapidez por meio das its bags, bolsas da moda cobiçadas pelo público alvo. Conforme explica Thomas (2008:152), “' 'it bags': os modelos de bolsa mais recentes e badalados que - graças às campanhas publicitárias das marcas de luxo e artigos em revistas de moda - se tornam o artigo da estação que ninguém pode deixar de ter."

De acordo com a citação, percebe-se que possuir determinada bolsa é uma obrigação para quem deseja ser reconhecido como conhecedor de moda e pertencer a 
Semiótica aplicada: campanha publicitária Journey, com Angelina Jolie, sob o espectro da teoria peirceana

de Carolina Boari Caraciola

um grupo aspiracional. A publicidade das marcas de luxo, por esse motivo, explora a imagem das bolsas com o objetivo de intensificar suas vendas através da obsolescência dos modelos.

Nesse anúncio, Angelina aparece com estilo natural, aparentemente sem maquiagem, fato que encontra congruência na nova tendência de beleza, que incentiva um visual natural. Nesse sentido, percebe-se uma volta ao pensamento clássico, que define que a beleza coincide com a verdade, "[...] porque, de certo modo, era a verdade que produzia Beleza." (Ecco 2010:317). Justifica-se, assim, a similaridade que encontramos entre a composição desse anúncio e as pinturas clássicas renascentistas.

A suposta antítese provocada pela simplicidade da modelo e o status que produtos de luxo conferem a seus usuários, é derrubada a partir das constatações de que os consumidores desse segmento não se identificam mais com o uso de imagens que contenham ostentação e mero glamour. De acordo com um estudo global realizado pela agência McCann, "A verdade sobre a riqueza”, foram identificados novos padrões de comportamento do público de alto poder aquisitivo. A pesquisa apontou que: “[...] o retrato de pessoas ricas envolvidas em atividades glamorosas e marcadas pela ostentação estão fora de moda. Hoje, o arquétipo masculino de riqueza não é mais o do homem maduro navegando em seu iate, tendo ao seu lado um troféu em forma de beldade com olhar blasé."3

$\mathrm{Na}$ realidade, a moda alicerçada na negação de artifícios embelezadores é construída através do uso de produtos cosméticos que simulam o efeito natural, o que determina uma realidade simulada. O luxo, por sua essência, não é simples nem natural, porém, mostra-se cada vez mais desvinculado de aspectos meramente ostentatórios.

O anúncio, dessa forma, acompanha a nova tendência do luxo, que se baseia na busca de autossatisfação. O consumidor de luxo, muito mais do que exibir as marcas que usa, busca uma recompensa, um prazer intimista que não precisa ser sinalizado por meio de logotipos.

A Louis Vuitton, acreditando nessa tendência, exibiu, no desfile da coleção outono/inverno 2013, produtos com logotipos reduzidos e, até mesmo, sem o monograma LV. Pesquisa realizada pelo instituto Ipsos apontou que "quanto maior o

\footnotetext{
${ }^{3}$ Material disponibilizado pela agência.
} 
Semiótica aplicada: campanha publicitária Journey, com Angelina Jolie, sob o espectro da teoria peirceana

de Carolina Boari Caraciola

logo, mais acessível é o preço da bolsa." ${ }^{4}$ Outro estudo, realizado pela empresa Bain\&Company, comprovou que há um público emergente, sobretudo em cidades como Pequim e Xangai, que prefere produtos de luxo mais discretos. O continente asiático, com exceção do Japão, responde por $28 \%$ das vendas da Louis Vuitton, o que justifica a preocupação com as preferências desse público. A mudança de logotipos proeminentes para mais discretos revela uma mudança no comportamento de uma parcela de consumidores de luxo que, em vez de ostentar, prefere ter um entendimento maior do mercado, obtendo uma experiência pessoal diferenciada. ${ }^{5}$

Sendo assim, cabe a Vuitton, e às demais marcas de luxo, encontrar um equilíbrio entre exclusividade e popularidade de seus produtos e inscrição de logotipos.

\section{REFERÊNCIAS BIBLIOGRÁFICAS}

ARNHEIM, R. Arte e percepção visual: uma psicologia da visão criadora: nova versão.

Trad. Ivonne Terezinha de Faria. São Paulo: Cengage Learning, 2014.

BURKE, P. A Fabricação do rei. A construção da imagem pública de Luís XIV. Trad. Maria Luiza X. de A. Borges. Rio de Janeiro: Jorge Zahar Editor, 1994.

ECCO, U. História da beleza. Trad. Eliana Aguiar. Rio de Janeiro: Record, 2010.

HALPERIN, I. Angelina \& Brad: a incrível história que não foi contada sobre Brad Pitt e Angelina Jolie, o casal "Brangelina". Trad. Mariana de Carvalho Mesquita Santana. São Paulo: Jardim dos Livros, 2012.

HELLER, E. A psicologia das cores: como as cores afetam a emoção e a razão. Trad. Maria Lúcia Lopes da Silva. São Paulo: Gustavo Gili, 2013.

MCCRACKEN, G. Cultura \& consumo II: mercados, significados e gerenciamento de marcas. Trad. Ana Carolina Balthazar. Rio de Janeiro: MAUAD, 2012.

NÖTH, W. Panorama da semiótica: de Platão a Peirce. São Paulo: Annablume, 2003.

OLIVEIRA, J; GARCEZ, L. Explicando a arte: uma iniciação para entender e apreciar as artes visuais. Rio de Janeiro: Ediouro, 2004.

\footnotetext{
${ }^{4}$ Disponível em: <http://wap.noticias.uol.com.br/midiaglobal/lemonde/2010/06/22/a-formula-magica-daindustria-do-luxo-logotipo-pequeno-produto-caro.htm>. Acesso em: 22 dez. 2014.

${ }^{5}$ Disponível em: <http://www.businessoffashion.com/2013/03/has-logo-fatigue-reached-a-tippingpoint.html>. Acesso em: $22 \mathrm{dez} .2014$.
} 
Semiótica aplicada: campanha publicitária Journey, com Angelina Jolie, sob o espectro da teoria peirceana

de Carolina Boari Caraciola

PEIRCE, C. S. Escritos coligidos. Seleção de Armando Moura D’Oliveira. Trad. Armando Moura D’Oliveira e Sergio Pomerangblum. São Paulo: Abril Cultural, 1974.

PEIRCE, C. S. Collected Papers. In: NÖTH, Winfried. Panorama da semiótica: de Platão a Peirce. São Paulo: Annablume, 2003.

PEREZ, C. Signos da marca: expressividade e sensorialidade. São Paulo: Pioneira Thomson Learning, 2004.

SANTAELLA, L. Semiótica aplicada. São Paulo: Pioneira Thomson Learning, 2012.

SANTAELLA, L. Matrizes da linguagem e pensamento: sonora, visual, verbal: aplicações na hipermídia. São Paulo: Iluminuras, 2005.

SANTAELLA, L; NÖTH, W. Estratégias semióticas da publicidade. São Paulo: Cengage Learning, 2010.

THOMAS, D. Deluxe: como o luxo perdeu o brilho. Trad. Ana Gibson. Rio de Janeiro: Elsevier, 2008.

TUNGATE, M. O império da beleza: como o marketing da L'Oreal, Natura, Avon, Revlon, Nívea e outras mudou nossa aparência. São Paulo: Seoman, 2013.

Artigo submetido: 30/04/2016

Artigo aprovado: 17/06/2016 